\title{
SYNTHETIC VISION ENHANCES SITUATION AWARENESS AND RNP CAPABILITIES FOR TERRAIN-CHALLENGED APPROACHES
}

\author{
Lynda J. Kramer ${ }^{*}$, Lawrence J. Prinzel $\mathrm{III}^{\dagger}$, Randall E. Bailey ${ }^{\ddagger}$, and J.J. (Trey). Arthur III ${ }^{\S}$ \\ NASA Langley Research Center, Hampton, VA
}

\begin{abstract}
The Synthetic Vision Systems (SVS) Project of Aviation Safety Program is striving to eliminate poor visibility as a causal factor in aircraft accidents as well as enhance operational capabilities of all aircraft through the display of computer generated imagery derived from an onboard database of terrain, obstacle, and airport information. To achieve these objectives, NASA 757 flight test research was conducted at the Eagle-Vail, Colorado airport to evaluate three SVS display types (Head-Up Display, Head-Down Size A, Head-Down Size X) and two terrain texture methods (photo-realistic, generic) in comparison to the simulated Baseline Boeing-757 Electronic Attitude Direction Indicator and Navigation / Terrain Awareness and Warning System displays. These independent variables were evaluated for situation awareness, path error, and workload while making approaches to Runway 25 and 07 and during simulated engine-out Cottonwood 2 and KREMM departures. The results of the experiment showed significantly improved situation awareness, performance, and workload for SVS concepts compared to the Baseline displays and confirmed the retrofit capability of the Head-Up Display and Size A SVS concepts. The research also demonstrated that the pathway and pursuit guidance used within the SVS concepts achieved required navigation performance (RNP) criteria.
\end{abstract}

\section{INTRODUCTION}

Limited visibility is the single most critical factor affecting both the safety and capacity of worldwide aviation operations. In commercial aviation alone, over 30-percent of all fatal accidents worldwide are categorized as controlled flight into terrain (CFIT), where a mechanically sound and normally functioning airplane is inadvertently flown into the ground, water, or an obstacle. The primary causes of these accidents are principally due to the lack of outside visual reference and lack of situation awareness. The NASA Aviation Safety Program's Synthetic Vision Systems (SVS) Project is developing technologies with practical applications that will eliminate low visibility conditions as a causal factor to civil aircraft accidents, as well as replicate the operational benefits of flight operations in unlimited ceiling and visibility day conditions, regardless of the actual outside weather or lighting condition. The technologies will emphasize the costeffective use of synthetic/enhanced vision displays, worldwide navigation, terrain, obstruction, and airport databases, and Global Positioning System (GPS)derived navigation to eliminate "visibility-induced" (lack of visibility) errors for all aircraft categories (transports, General Aviation, rotorcraft). A major thrust of the SVS Project is to develop and demonstrate affordable, certifiable display configurations which provide intuitive out-the-window terrain and obstacle information, including guidance information for precision navigation and obstacle/obstruction avoidance for Commercial and Business aircraft.

The safety benefit of SVS is projected to be the result of an intuitive cockpit display of terrain and obstacles that should help reduce, or even prevent, CFIT, which is the single greatest contributing factor to fatal worldwide airline and general aviation accidents. ${ }^{1}$ Other safety benefits include reduced runway incursions and loss-of-control accidents. ${ }^{2}$ Operational benefits potentially include more approach and departure options and lower visibility minimums for SVS -equipped aircraft. ${ }^{3,4}$

Because intuitive perspective displays can naturally depict effective precision pathway (tunnel) guidance concepts, SVS may also significantly improve flight path tracking performance and help meet new FAA required navigation performance (RNP) criteria. RNP is a statement of the navigation performance accuracy necessary for operation within a defined airspace. RNP type is a designator according to navigational performance accuracy in the horizontal plane (lateral and longitudinal position fixing). This designator invokes all of the navigation performance requirements

\footnotetext{
* AIAA Associate Fellow, Aerospace Technologist

$\dagger$ Aerospace Technologist

$¥$ AIAA Member, Aerospace Technologist

$\S$ AIAA Member, Aerospace Technologist
} 
associated with the applicable RNP number, which is a containment value. For example, RNP-1 means that for at least $95 \%$ of the time the navigational performance in the horizontal plane, or the total horizontal system error, is less than $1.0 \mathrm{nmi}$. In addition to requiring $95 \%$ positioning accuracy for RNP operations, these types of procedures also require integrity of the positioning accuracy at $99.999 \%$ at 2 x RNP number. In our example above with an RNP-1, the position accuracy within $2.0 \mathrm{nmi}$ of the ownship ( $2 \mathrm{x}$ RNP value of 1.0 nmi) would have to be guaranteed to be correct $99.999 \%$ of the time to enable RNP-1 operations.

There are three lateral components of navigation error: path definition error, path steering error, and position estimation error. ${ }^{5}$ These errors, defined in the following, represent the total horizontal system error of the airplane and are the difference between the aircraft's true position and desired position:

$>$ The path definition error is the difference between the defined path and the desired path at a specific point.

$>$ The path steering error is the distance from the estimated position to the defined path. It includes both the flight technical error (FTE) and display error. FTE is the accuracy with which the aircraft is controlled as measured by the indicated aircraft position with respect to the indicated command or desired position.

$>$ The position estimation error, also referred to as the ship's actual navigation performance (ANP), is the difference between the true position and the estimated position.
Vertical navigation (VNAV) capability further enhances flight operations by enabling the specification of a flight path vertically for the lateral flight path. VNAV ensures that for at least $99.7 \%$ of the time the navigational performance in the vertical plane, or the total vertical system error, is less than a specified altitude deviation measure based on the airspace being flown in (below 5000 feet MSL, 5000-10000 feet MSL, above 10000 feet MSL) and the type of flight operation (level flight/climb/descent or flight along specified vertical profile) being performed (see Table 1).

There are four vertical components of navigation error: altimetry system error, vertical path steering error, vertical path definition error, and horizontal coupling error. ${ }^{5}$ These errors, defined in the following, represent the total vertical system error of the airplane and are the difference between the aircraft's true vertical position and desired vertical position at the true lateral position:

$>$ Altimetry system error is the error attributable to the aircraft altimetry installation including position effects resulting from normal aircraft flight attitudes.

$>$ The vertical path steering error is the distance from the estimated vertical position to the defined path. It includes both FTE and display error.

$>$ The vertical path definition error is the vertical difference between the defined path and the desired path at the estimated lateral position.

$>$ The horizontal coupling error is the vertical error resulting from horizontal along track position estimation error coupling through the desired path.

Table 1. Vertical Accuracy Performance Requirements

\begin{tabular}{|l|l|l|l|l|l|l|}
\hline Error Source & \multicolumn{4}{|l|}{$\begin{array}{l}\text { Level Flight Segments } \\
\text { and Climb/Descent } \\
\text { Intercept of Clearance } \\
\text { Altitudes (MSL) }\end{array}$} & $\begin{array}{l}\text { Approach } \\
\text { along Specified } \\
\text { Vertical Profile } \\
\text { (MSL) }\end{array}$ \\
\hline & $\begin{array}{l}\text { At or Below } \\
5000 \mathrm{ft}\end{array}$ & $\begin{array}{l}5000 \mathrm{ft} \text { to } \\
10000 \mathrm{ft}\end{array}$ & $\begin{array}{l}\text { Above } \\
10000 \mathrm{ft}\end{array}$ & $\begin{array}{l}\text { At or Below } \\
5000 \mathrm{ft}\end{array}$ & $\begin{array}{l}5000 \mathrm{ft} \text { to } \\
10000 \mathrm{ft}\end{array}$ & Above $10000 \mathrm{ft}$ \\
\hline Altimetry & $90 \mathrm{ft}$ & $200 \mathrm{ft}$ & $250 \mathrm{ft}$ & $140 \mathrm{ft}$ & $265 \mathrm{ft}$ & $350 \mathrm{ft}$ \\
\hline $\begin{array}{l}\text { RNAV } \\
\text { Equipment }\end{array}$ & $50 \mathrm{ft}$ & $50 \mathrm{ft}$ & $50 \mathrm{ft}$ & $100 \mathrm{ft}$ & $150 \mathrm{ft}$ & $220 \mathrm{ft}$ \\
\hline $\begin{array}{l}\text { Flight } \\
\text { Technical }\end{array}$ & $150 \mathrm{ft}$ & $240 \mathrm{ft}$ & $240 \mathrm{ft}$ & $200 \mathrm{ft}$ & $300 \mathrm{ft}$ & $300 \mathrm{ft}$ \\
\hline $\begin{array}{l}\text { Total Root- } \\
\text { Sum-Square } \\
\text { (RSS) }\end{array}$ & $190 \mathrm{ft}$ & $320 \mathrm{ft}$ & $350 \mathrm{ft}$ & $265 \mathrm{ft}$ & $430 \mathrm{ft}$ & $510 \mathrm{ft}$ \\
\hline
\end{tabular}


To date, much of the SVS research has focused on introducing SVS display technology into as many existing aircraft as possible by providing a retrofit approach. This approach employs existing head down display (HDD) capabilities for glass cockpits (i.e., cockpits already equipped with SVS-compatible HDDs) and head-up display (HUD) capabilities for the other aircraft. A major NASA flight test at Dallas/Fort Worth International Airport (DFW) and several simulator studies have occurred for assessment and evaluation of the SVS developments and the retrofit approach. The HDD objective of these studies was to examine whether an SVS display could be retrofitted into an Electronic Flight Instrumentation System (EFIS) Size "A" (e.g., B757-200) Electronic Attitude Direction Indicator (EADI) and Size "D" (e.g., B777) Primary Flight Display (PFD). A Size "X" (8 in. x 10 in.) headdown display was also tested that may represent the display area available on future aircraft. The HUD objective was to examine the feasibility of retrofitting SVS display technology with HUDs for aircraft without SVS-compatible HDDs. The feasibility of retrofitting SVS display technology with HUDs was verified for nighttime operations. ${ }^{6}$ Two terraintexturing techniques were also evaluated during the research. One method of terrain texturing, generic texturing, involved the selection of terrain color based on absolute altitude. The other method of terrain texturing, photo-realistic texturing, employed full-color ortho-rectified aerial photographs draped over the elevation model. The results of those studies confirmed that an SVS display, with pilot-selectable field of view (FOV), could be incorporated as part of an EFIS suite and effectively replace an EADI or PFD. Regardless of HDD display size, and for the nighttime HUD application, pilots reported greater situation awareness and had lower FTE while operating with the SVS displays compared to conventional displays. 6 For both HDD and HUD applications, no significant performance effects were found between texturing techniques, although most of the pilots preferred the photo-realistic terrain texturing technique to the generic texturing technique.

This research identified the potential of SVS to enhance situation awareness and improve aviation safety during approaches to terrain and operationally complex airports. ${ }^{6,7,8}$ The DFW flight test showed that all SVS display concepts provided precise path control and significantly improved spatial awareness for approaches under nighttime conditions. However, although the fixed-based simulator results had provided convincing data on the efficacy of SVS for terrain-challenged environments, these results had yet to be replicated and validated under operational flight test conditions like that conducted at DFW in 2000. (The 1999 flight test / demonstration of the SVS technology did make approaches to the Asheville, NC airport, but no empirical data was collected to substantiate the claims that SVS was effective in terrain-challenged environments.) Therefore, the Aviation Safety program and SVS project conducted a flight test in the vicinity of Eagle County Regional Airport, CO (FAA identifier: EGE) to further examine the utility, capabilities, and potential of SVS to enhance situation awareness and improve pilot performance for operations in mountainous environments. This paper documents that flight test experiment.

\section{METHODOLOGY}

Subjects

Six evaluation pilots, representing three airlines, FAA and Boeing flew 12 research flights totaling 51.6 flight hours. Eighty-four data flight test runs were conducted to evaluate the NASA display concepts with 49 being flown to EGE Runway 07 and 35 flown to Runway 25. All participants were rated B-757 captains with operating experience at EGE. Prior to deployment, all evaluation pilots received a one-day training course (briefing and simulator session) at NASA Langley Research Center (LaRC) to familiarize them with the SVS display concepts.

\section{$\underline{\text { Flight Test Vehicle and Equipment }}$}

Aircraft. The flight test was conducted using the NASA LaRC Boeing 757 (B-757) Airborne Research Integrated Experiment System (ARIES) aircraft (see Figure 1). The left seat in the Boeing 757 was occupied by the Evaluation Pilot (EP). The right seat was occupied by the NASA Safety Pilot (SP). The left seat included the installation of an SVS Research Display (SVS-RD) and an overhead HUD projection unit (see Figure 2). A vision restriction device (VRD) (see Figure 3) was placed in the left-seat forward windscreen to block the EP's forward vision and thus simulate instrument meteorological conditions (IMC) when needed experimentally.

SVS-RD. The SVS-RD is a Commercial Offthe-Shelf 18.1" diagonal high brightness Liquid Crystal Display monitor, modified for installation over the forward instrument panel cluster on the left hand side of the ARIES cockpit (see Figure 2). Since the SVS-RD was capable of generating high resolution, multisized displays, this monitor 
displayed all head-down display concepts for evaluation. The SVS-RD has 1280 vertical by 1024 horizontal pixel resolution (approximately 90 pixels per inch) with 900 nits brightness for reasonable sunlight readability in the Boeing 757 aircraft.

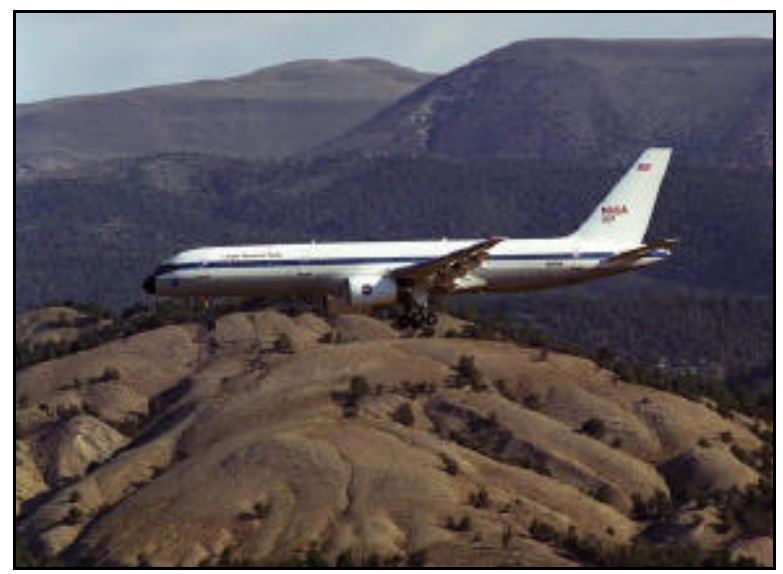

Figure 1. NASA 757 during EGE approach.

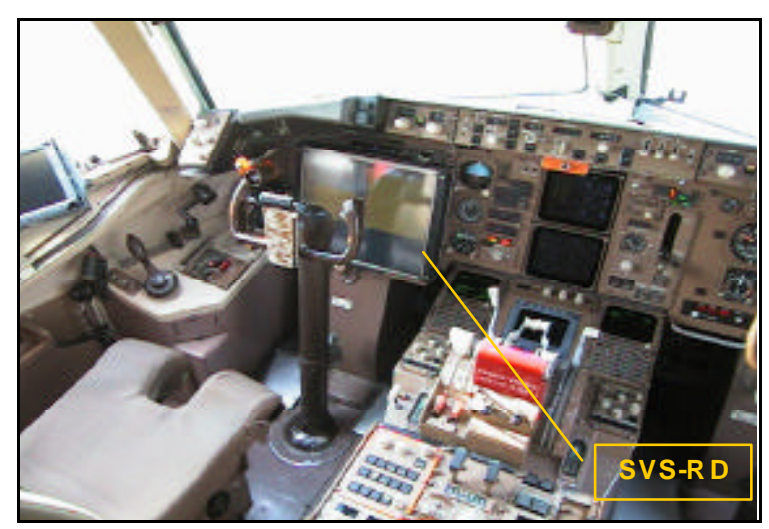

Figure 2. SVS-RD installed in ARIES 757 aircraft.

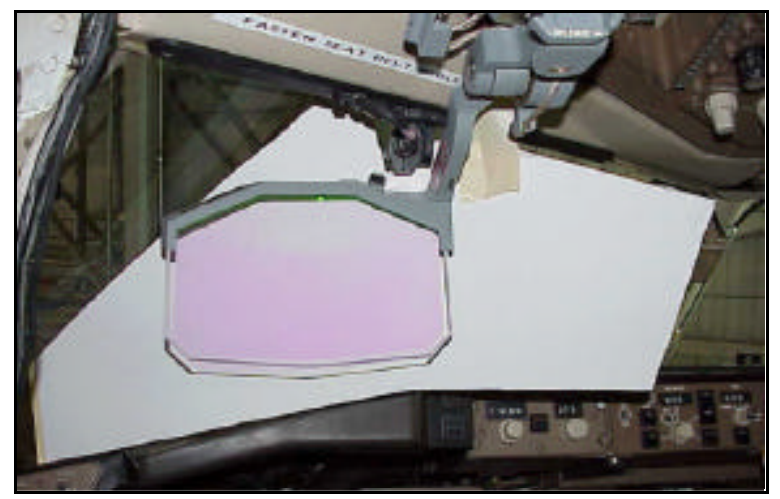

Figure 3. VRD in ARIES 757 aircraft.
Synthetic Vision Systems Graphic Engine (SVSGE). The NASA SVS display concepts were generated by two Intergraph $\mathrm{Zx} 10$ personal computers using Windows NT TM. The Zx10 was a dual $866 \mathrm{MHz}$ Pentium III processor with 1+ Gigabytes of Random Access Memory. A video card from 3D Labs, Inc. - the Wildcat ${ }^{\mathrm{TM}} 4210$ - provided SXGA, 1280x1024 at $60 \mathrm{~Hz}$ anti-aliased (SuperScene ${ }^{\mathrm{TM}}$ enabled) video rendering at real-time $(>30 \mathrm{~Hz})$ update rates to drive the SVS-RD. Symbology was generated using the OpenGL application programming language (API). For the HUD raster input, a XGA $(1024 \times 768)$ video output from the Zx10 was scan converted to RS-343 (875 line, $30 \mathrm{~Hz}$ Interlaced) format video.

Head-Up Display. The left-seat, overhead Dassault projection HUD was interfaced with a research Flight Dynamics Head-Up Guidance System (HGS)-4000 computer. The HGS -4000 was modified by NASA to conduct research on certain HUD configurations. The HGS -4000 could be placed in a "Normal" mode, which triggered the HGS-4000 to function with its nominal commercial functionality, or in a "Research" mode. For this flight test, the HGS-4000 was operated in the "Research" mode, which triggered the HGS-4000 to include some special purpose symbology, as described in the following.

The HGS -4000 computer is stroke-on-raster capable using an RS-343 raster video format input. The HGS-4000 raster input consisted of the synthetic vision terrain and tunnel symbology while retaining high-quality stroke symbology for primary flight information (e.g., airspeed, altitude). The HGS-4000 "Primary Mode" stroke symbology set was used in the flight test, albeit with the compass rose symbol set removed when in "Research" mode. The raster image consisted of "layers" of imagery and symbology. Synthetic terrain imagery formed the "Background Raster". Guidance symbology and tunnel ("Pathway-in-the-Sky") symbology were combined to create the "Foreground Raster". The FOV of the ARIES HUD was measured to be $22^{\circ}$ vertical by $28^{\circ}$ horizontal. Note that to maintain conformality with the outside world, the FOV for the HUD raster image was fixed and could not be varied by the EP. As the minification/magnification factor was thus unity, the condition was colloquially known as unity FOV.

Brightness and contrast controls were provided: a) Stroke-only brightness; b) Overall raster image brightness; c) Background raster (synthetic terrain 
imagery) contrast; d) Background raster brightness; and e) Foreground raster (guidance and tunnel symbology) brightness. Although somewhat complex, these controls gave the EP the needed flexibility to tailor the image.

A HUD declutter button was available on the control yoke. The declutter button cycled the HUD symbology between four modes: 1) No declutter All display elements present; 2) Foreground raster (raster guidance symbology \& tunnel) deleted; 3) All HUD raster deleted; and, 4) All display elements (both stroke and raster) deleted.

Field of View Control. FOV control for the NASA HDD SVS concepts was available to the pilot on a four-position wafer switch on a conveniently located center console panel. The FOV options were: Unity, $30^{\circ}, 60^{\circ}$, and $90^{\circ}$. The FOV provided at the "unity" setting changed depending upon the size of the experimental HDD condition being flown.

\section{Evaluation Tasks}

FMS Runway 25 Approach and Cottonwood-2 Departure ("FMS25"). The FMS25 task started on a dogleg to the final approach course, level at $13,100 \mathrm{ft}$ MSL (see Figure 4). At the waypoint TALIA, approximately $16 \mathrm{~nm}$ from the airfield - the final approach fix - the turn to the offset localizer

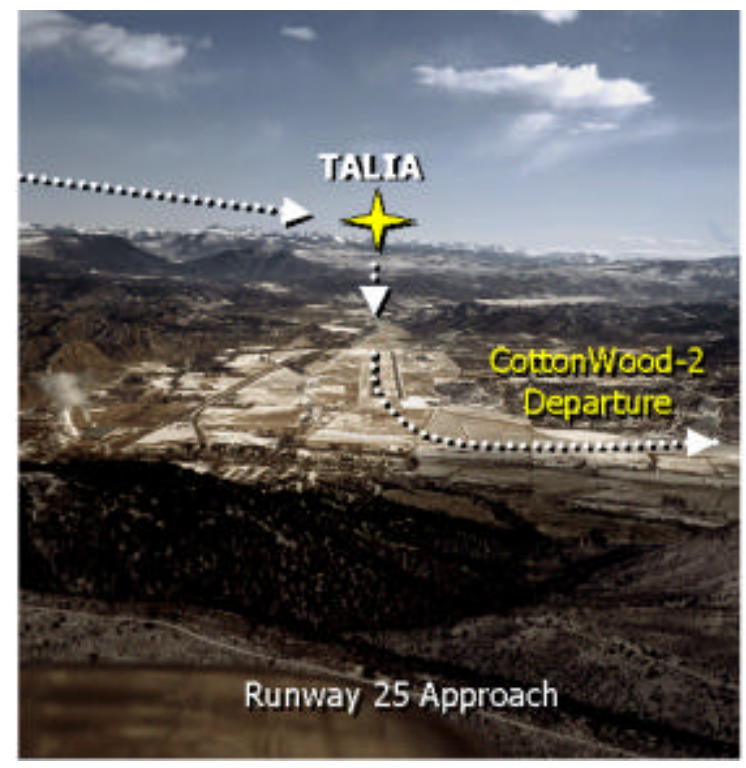

Figure 4. Approach and departure tasks flown at EGE.

Visual Arrival to Runway 07 and KREMM Departure ("Visual 07"). The Runway 07 approach task started with the same FMS25 approach approach course was made and the descent into the EGE local operating area was initiated. The initial descent angle from TALIA was nominally 4.4 degrees. Several descent angle changes were commanded until approximately $1000 \mathrm{ft}$ Above Field Level (AFL), where the guidance directed a 3 degree descent to the runway touchdown zone. A missed approach was declared before $200 \mathrm{ft}$ Above Ground Level (AGL) and the NASA SP took over control of the 757 from the EP and performed a leveloff and reconfigured the aircraft for the departure. The missed approach mimicked the nominal FMS-based path (the Cottonwood-2 departure) with a left turn well before the departure end of the runway to ensure clearance from Snow Mountain - an $1800 \mathrm{ft}$ AFL peak approximately $2 \mathrm{~nm}$ from EGE. After the departure turn, the EP was given control of the aircraft and flew the departure task. A reduced climb angle departure, loosely replicating the climb of a moderately loaded 757 in a single engine condition, was flown. The simulated single engine departure provided a worse-case operational scenario but a best-case condition for terrain awareness testing. The simulated single-engine Cottonwood-2 departure required a turn at Waypoint F219G to maintain terrain and obstacle clearance along Cottonwood Pass. The departure concluded upon reaching 10,000 ft Mean Sea Level (MSL), which typically occurred just prior to Waypoint F204K.

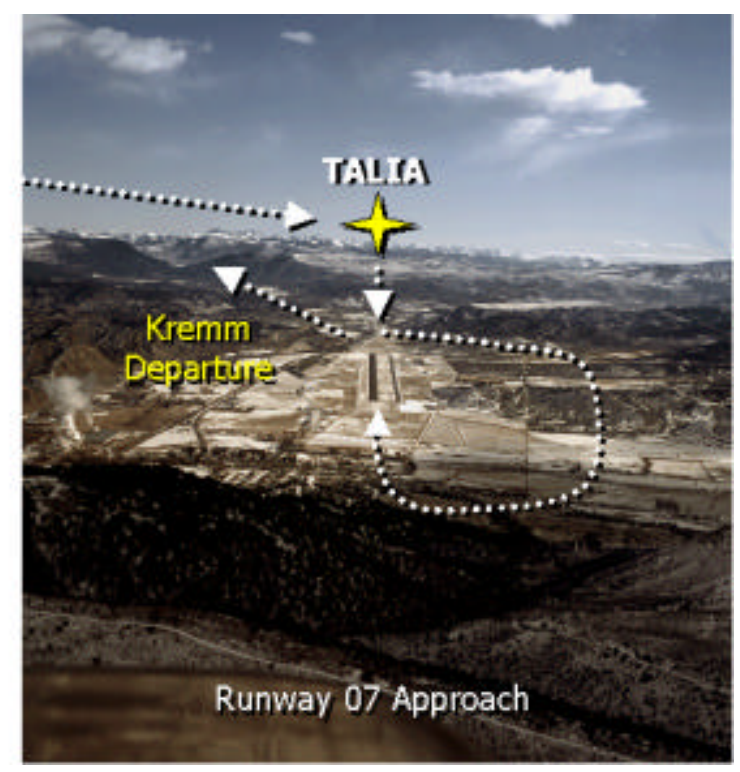

procedure (see Figure 4). At approximately $5.3 \mathrm{~nm}$ DME, a level off at $8100 \mathrm{ft}$ MSL was commanded followed by an approximate 20 degree left turn into a modified downwind leg. When about abeam the 
Runway 07 end, a descending right turn was flown for landing. For this flight test, a go-around was declared before $200 \mathrm{ft}$ AGL and executed by the NASA SP. The SP took over control of the 757 and performed a level-off and reconfigured the aircraft for the departure. A reduced climb angle departure was again established to provide a best-case testing condition. The missed approach procedure (following the published KREMM departure procedure) was a left turn to a 050 heading once off the departure end of the runway. After the departure turn, the EP was given control of the aircraft and flew the remainder of the departure task. A 050 heading was held until intercepting the 059 radial from the Snow VOR beacon. The run ended upon climbing along the 059 radial through 10,000 ft MSL.

\section{$\underline{\text { Display Conditions }}$}

Six NASA SVS tactical display configurations were evaluated in comparison to a simulated Baseline Boeing-757 EADI which included a Navigation Display (ND) with simulated Terrain Awareness and Warning System (TAWS) information (see Figure 5). The SVS configurations were obtained by presenting SVS terrain databases of two terrain texturing types (generic or photo-realistic) on three displays: a HUD and two HDD sizes (A or X). The HUD concepts utilized the Baseline EADI concept head down, along with the TAWS ND.

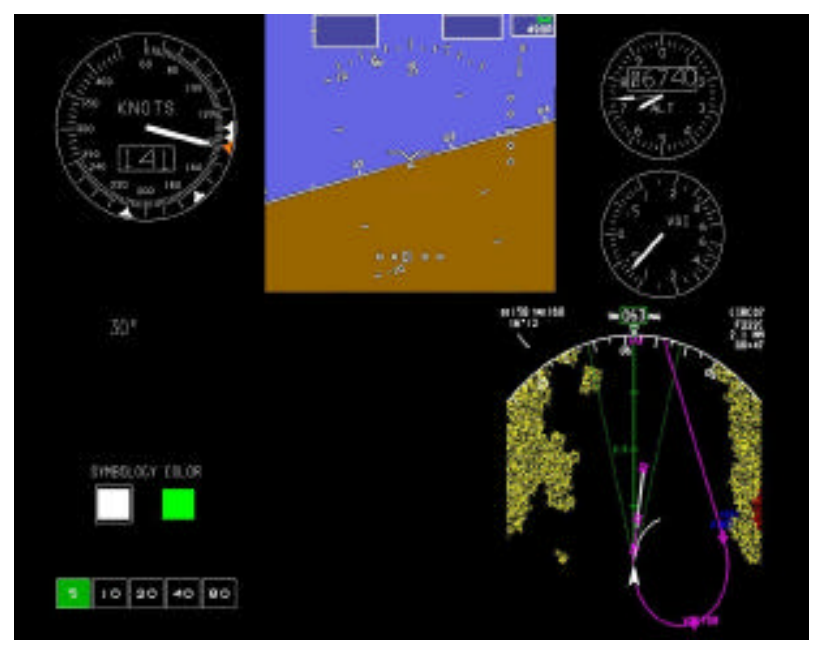

Figure 5. Baseline display.

Terrain Texturing Types. Terrain-texturing refers to the method used to fill the polygons that comprise the rendered terrain database. The two texturing concepts tested were elevation-based colorcoding, or generic, and photo-realistic. The generic texturing concept consisted of applying color based on interpolation between index color bands that corresponded to different absolute terrain elevation levels. Lower terrain levels were colored with darker colors, while higher terrain levels were assigned lighter colors. A shade of green was set to the field elevation. The photo-realistic texturing was derived from full color ortho-rectified aerial photographs. The resulting scene was a highly realistic view due to the photographic imagery employed.

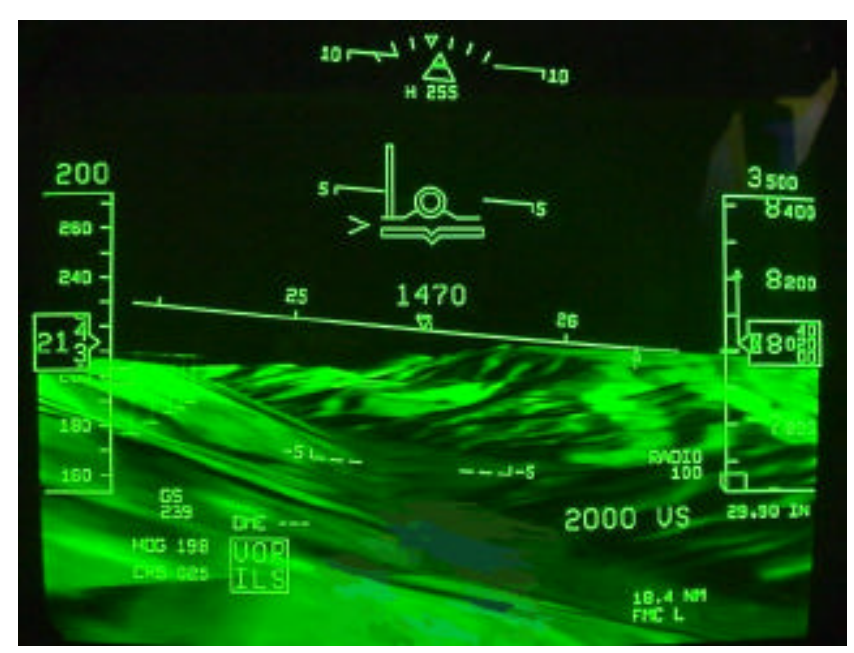

Figure 6. Head-Up Display with generic texturing.

SVS HUD Concept. As mentioned previously, the NASA SVS Project is investigating the potential of HUD technology as a retrofit solution for display of terrain database SVS concepts in non-glass cockpits. The terrain database scene is presented on the HUD as a raster image with stroke symbology overlaid upon it (see Figure 6). It is similar to enhanced vision system (EVS) concepts, which typically use advanced imaging sensors to penetrate weather phenomena such as darkness, fog, haze, rain, and/or snow, and are displayed in the HUD raster channel. However, in the SVS HUD concept, the terrain database scene replaces the sensor image. The HUD database image is always available to be displayed and is not compromised by weather penetrating capabilities or other sensor anomalies of an EVS sensor. Also, unlike EVS displays, the SVS HUD concept shows a "clear sky" rather than a sensor image of the sky, so there is no obstruction of that area of the display. Below the horizon, the raster image may obstruct the view of the outside real world in visual meteorological conditions, particularly if the raster brightness is not controlled appropriately by the pilot. This possible obstruction was a concern so declutter control was provided to the pilot and training was given to mitigate this issue. In addition to the raster, nominal flight information symbology characteristic of most airline HUDs was overlaid on 
the HUD imagery.

HDD Tactical Display Sizes. Two different SVS-HDD configurations were evaluated during this flight test to explore retrofit concepts of SVS display technology into existing glass cockpits (cockpits already equipped with raster-capable HDDs). One display configuration, referred to as the SVS Size A, was similar to a B-757-200 EADI with separate airspeed, altitude, and vertical speed gauges, with the addition of SVS information (see Figures 7-8). The

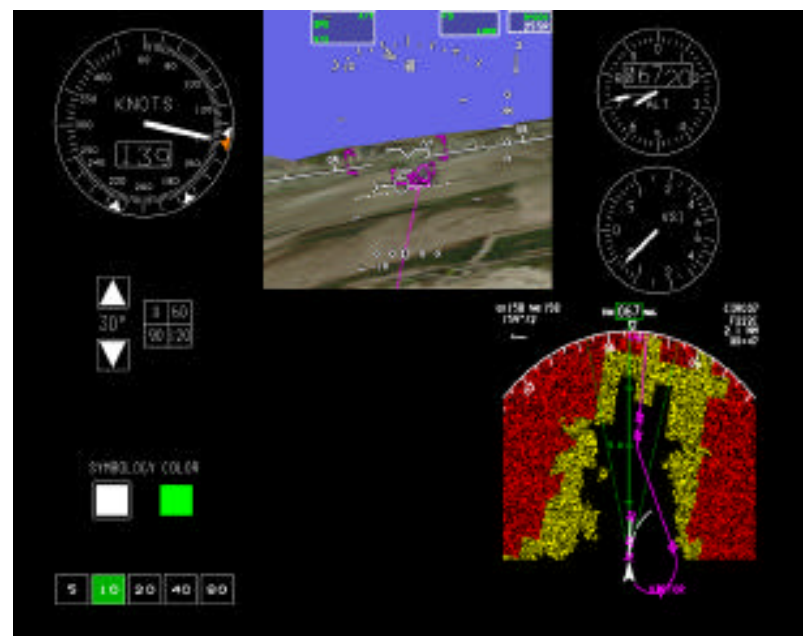

Figure 7. Size A with photo-realistic texturing.

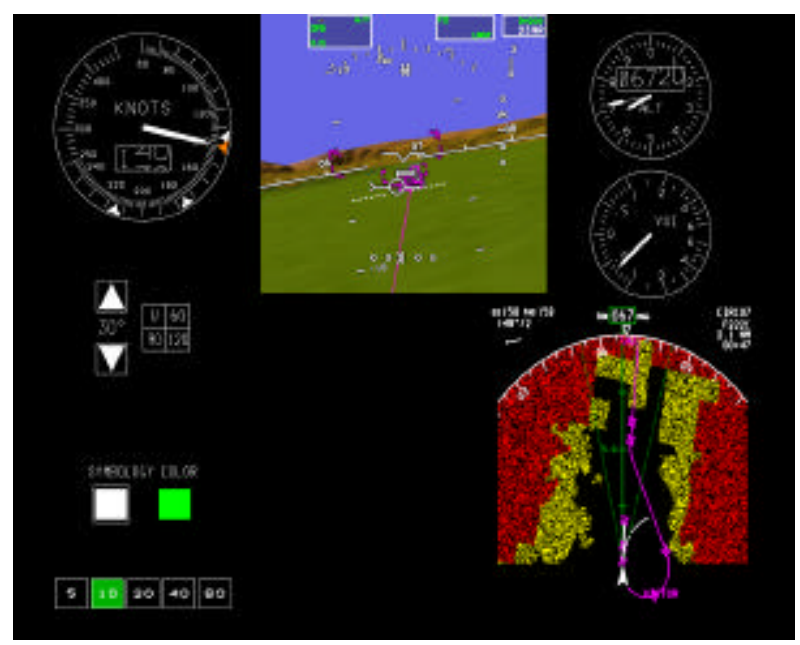

Figure 8. Size A with generic texturing.

\section{Tunnel and Path Guidance Depiction}

Raw data (path error) information was depicted on each display concept by using path deviation indicators on the localizer and glideslope scales.

SVS Displays. A tunnel depiction was second HDD configuration, referred to as Size X, featured an enlargement of an integrated PFD to replicate future SVS HDD concepts (see Figure 9 10). Evaluation pilots could control the FOV of the HDD EADI and PFD concepts evaluated to enhance display effectiveness. As mentioned previously, a conventional Size A EADI HDD configuration with no SVS information was also provided as a baseline for comparison purposes (see Figure 5). Terrain information was available on the Navigation Display for all of the concepts.

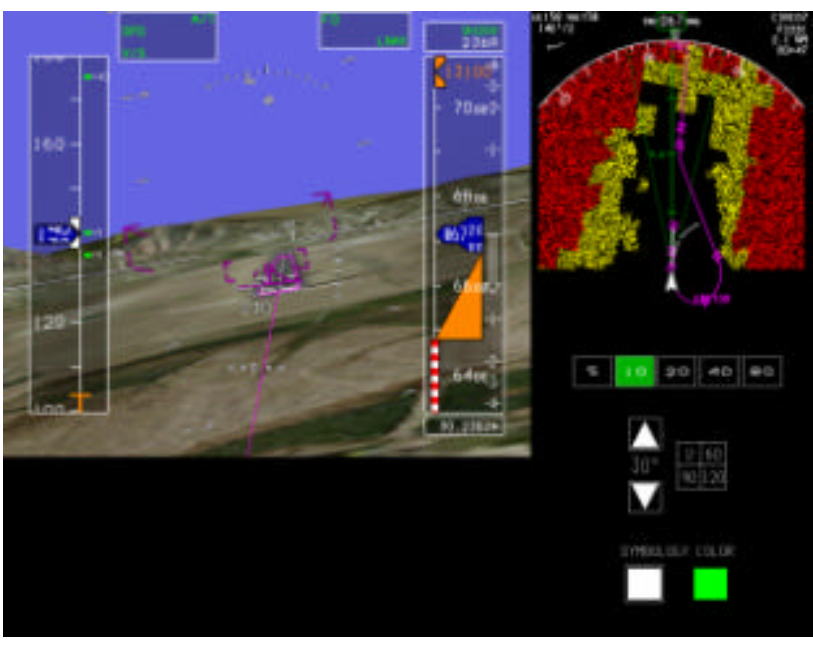

Figure 9. Size $\mathrm{X}$ with photo-realistic texturing.

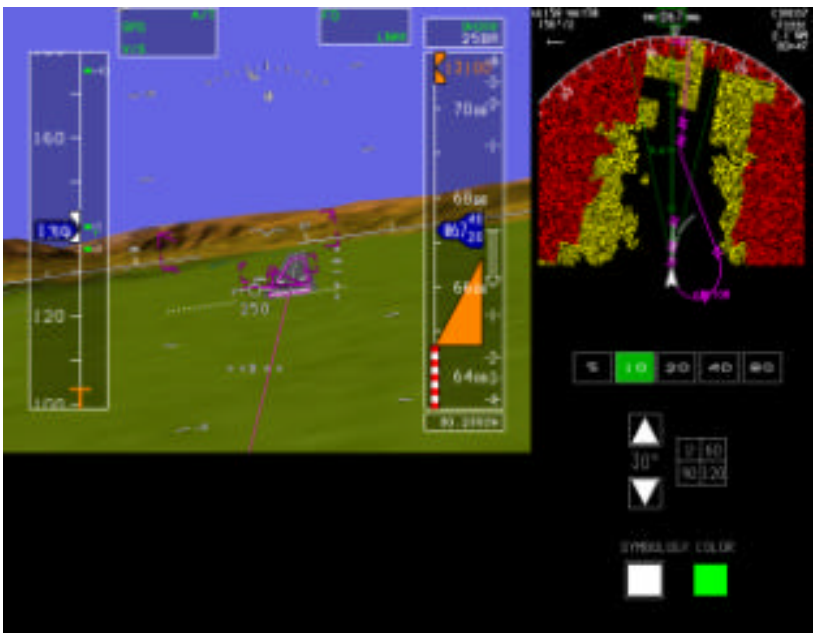

Figure 10. Size $\mathrm{X}$ with generic texturing.

nominally drawn for approach guidance on the SVS concepts (Size A, Size X, HUD) to increase the pilot's situational awareness of the desired aircraft trajectory. The objective was to create path awareness yet not to obscure or occlude the terrain portrayal of the Synthetic Vision image by display clutter. With this objective, a "minimalist" tunnel 
was constructed using "crow's feet". The crow's feet were spaced at $0.2 \mathrm{~nm}$ along the desired path. The top crow's feet of the tunnel were only displayed up to $1.0 \mathrm{~nm}$ in front of the aircraft. The bottom crow's feet are linearly scaled in brightness so, by 3.0 $\mathrm{nm}$ from own-ship, the brightness of the bottom crow's feet was reduced to zero.

Additional guidance information for the SVS display concepts was provided by a ghost airplane symbol. The ghost airplane was positioned by a modified form of pursuit guidance to keep the aircraft trajectory tracking the tunnel. ${ }^{9}$ During the missed approach tasks, the tunnel and ghost aircraft were removed and a single cue flight director based on the ship's FMS was drawn to provide speed-on-pitch and roll steering commands.

Baseline Display. The Baseline condition had no tunnel or ghost airplane guidance symbol, but it did have path deviation indicators on the localizer and glideslope deviation scales. Because of difficulties encountered with the ship systems' FMS and flight director, approach guidance for the Baseline Concept varied according to Task. For the FMS 25 approach task, flight director guidance was provided on conventional dual cue flight director needles. For the Visual 07 approach task, no flight director guidance was available, and the pilots resorted to the raw lateral and vertical path deviation indicators. During the missed approach tasks, a dual cue flight director based on the ship's FMS was drawn to provide speed-on-pitch and roll steering commands.

\section{Organization of Trials}

Approximately 6 evaluations per flight were planned. Each evaluation consisted of the approach and departure task to either Runway 25 ("FMS25") or Runway 07 ("Visual 07") (see Figure 11). For aircraft performance considerations (fuel weight), Runway 07 evaluations were planned for the latter portions of each flight. Because of the desire to ensure collection of HUD flight test data, the HUD runs were always flown first of all the SVS display concepts. The experimental run matrix was developed with these constraints in place.

Generally, an EP's first experimental run used the Baseline concept with no VRD installed. In fact, whenever the Baseline condition was evaluated, the VRD was not installed. The second experimental run used the HUD without the VRD installed. After the first two experimental runs were flown, the VRD was installed and used for the remaining display concept evaluations (except as noted for the Baseline condition). The first three runs were always FMS25 runs to ensure some fuel weight reduction before attempting the more challenging Visual 07 runs. The SVS Size A and X concept runs, along with SVS texture type variations, were balanced across pilots in the usual manner to alleviate learning and fatigue effects.

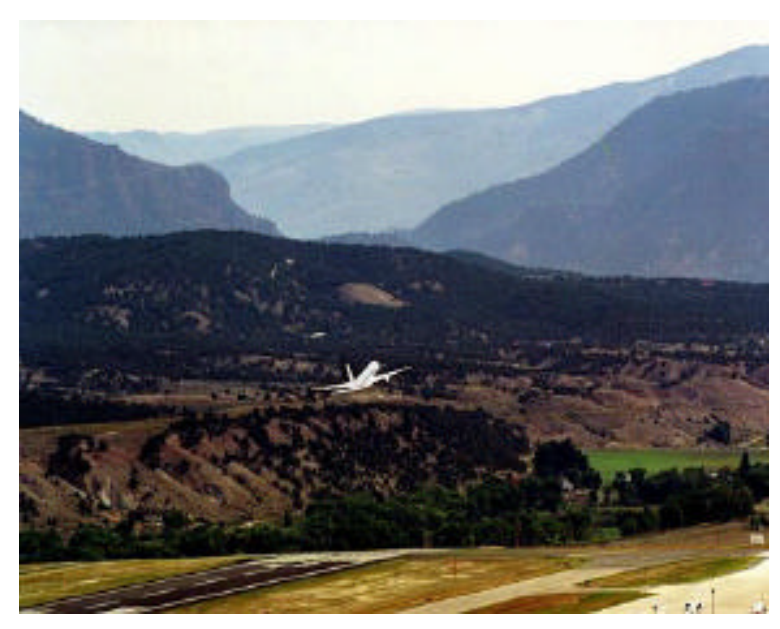

Figure 11. NASA 757 during KREMM departure.

\section{$\underline{\text { RESULTS }}$}

\section{Improved Path Performance}

Display/Task Analyses. Separate ANOVAs were performed on the Root Mean Square (RMS) lateral path deviation and the RMS vertical path deviation for the entire approach with display type (Baseline, Size A, Size X, HUD), task (FMS25, Visual 07), and pilot as the independent variables.

Six runs (4 HUD, 1 Size A and 1 Baseline) were not included in these analyses due to known data contamination problems (operational restrictions, equipment problems, raster guidance symbology limitations, and cockpit distractions). For example, two HUD runs were excluded due to a low cloud ceiling of 12,500 feet MSL that prevented the pilot from flying the required altitude of 13,100 feet MSL during the inbound approach to Waypoint TALIA (operational restriction). Another HUD run was excluded due to a pilot's inability to discern the raster guidance symbology from the raster terrain, which caused him to miss the initial descent at Waypoint TALIA (symbology limitation).

Display type $(\mathrm{F}(3,61)=102.143, \mathrm{p}<.001)$ was highly significant for the measure of RMS lateral path error during the entire approach (see Figure 12). Post hoc 
tests (using SNK with $\alpha=.05$ ), showed that significantly worse tracking of the lateral path occurred when using the Baseline Concept (missing data for FMS25; raw data only for Visual 07: mean $=818 \mathrm{ft}, \mathrm{n}=5$ ) as compared to the three SVS Concepts, with which the pilots had precision pathway guidance during each task: Size A (mean = $61 \mathrm{ft}, \mathrm{n}=19)$, Size $X($ mean=51 ft, $\mathrm{n}=22)$, HUD (mean=67 ft, $\mathrm{n}=27$ ). There were no significant differences among the SVS concepts for this measure. Task, pilot, and the second order interaction of display type and task were not significant $(\mathrm{p}>.05)$ for this measure.

Display type $(\mathrm{F}(3,65)=18.227, \mathrm{p}<.001)$ was highly significant for the measure of RMS vertical path error during the entire approach. Post hoc tests (using SNK with $\alpha=.05$ ) showed that the vertical path deviation when flying with the Baseline Concept (the pilots had differing conventional guidance information across the two tasks: mean $=147 \mathrm{ft}, \mathrm{n}=10$ ) was significantly worse than when flying with any of the three SVS Concepts, with which the pilots had precision pathway guidance: Size A (mean $=38 \mathrm{ft}$, $\mathrm{n}=19)$, Size $\mathrm{X}($ mean=40 ft, $\mathrm{n}=22)$, HUD (mean=32 $\mathrm{ft}, \mathrm{n}=27$ ). There were no significant differences among the SVS concepts for this measure. Task, pilot, and the interaction between display type and task were not significant ( $p>.05)$ for this measure.

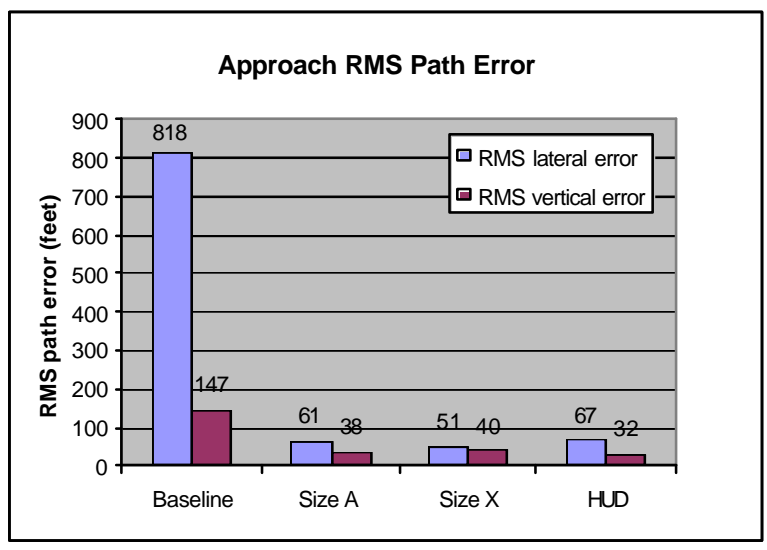

Figure 12. RMS lateral and vertical path error over approach path.

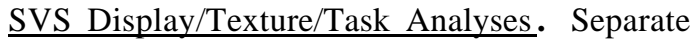
ANOVAs were performed on the RMS lateral path deviation and the RMS vertical path deviation for the entire approach with SVS display type (Size A, Size $\mathrm{X}, \mathrm{HUD})$, texture type (generic, photo-realistic), task (FMS25, Visual 07), and pilot as the independent variables. For the reasons cited previously in the
Approach Path Display/Task Analyses section, six runs were excluded from these analyses. Neither the main factors nor the second order interaction between SVS display type and texture type was significant ( $p>.05)$ for the measure of RMS lateral path error during the entire approach. SVS display type $(\mathrm{F}(2,56)=8.449, \mathrm{p}=.001)$ and task $(\mathrm{F}(1,56)=12.884$, $\mathrm{p}=.001)$ were significant for the measure of RMS vertical path error during the entire approach. Post hoc tests (using SNK with $\alpha=.05$ ) showed that the vertical path deviation (see Figure 12) when flying with the HUD SVS concept (mean=32 ft, $\mathrm{n}=27$ ) was significantly better than when flying with the headdown SVS Concepts: Size A (mean=38 ft, $\mathrm{n}=19)$ and Size $X($ mean $=40 \mathrm{ft}, \mathrm{n}=22)$. The pilots had worse tracking of the vertical path during the FMS25 approach (mean=39 feet) than with the Visual 07 approach (mean=34 feet). Texture type and the second order interaction between SVS display type and texture type were not significant $(p>.05)$ for the measure of RMS vertical path error during the entire approach.

\section{$\underline{\text { Required Navigation Performance Criteria }}$}

For the reasons cited previously in the Approach Path Display/Task Analyses section, six runs were excluded from the Lateral Navigation analyses and Vertical Navigation analyses described below.

Lateral Navigation Analyses. Lateral path FTE histograms were generated over the entire approach for the four display concepts (Baseline, Size A, Size $X, H U D)$. The path steering error component of the RNP calculation includes both FTE and display error. For this analysis, it was assumed that display error was negligible, so FTE was the only component of path steering error. It was also assumed that the other two components (path definition error and position estimation error) of the RNP calculation would be equivalent across the display concepts evaluated.

With these assumptions, the SVS concepts yielded a horizontal FTE navigational accuracy of $0.05 \mathrm{nmi}$ at least $95 \%$ of the time; while the Baseline concept was only able to yield a horizontal FTE navigational accuracy of $0.25 \mathrm{nmi}$ at least $95 \%$ of the time. As such, based on the FTE distributions, the SVS concepts (Size A, Size X, HUD) would enable RNPtype operations that were five times smaller than those that would be allowed with the Baseline EADI concept.

Vertical Navigation Analyses. Vertical path FTE histograms were generated over the entire approach for the four display concepts (Baseline, Size A, Size 
$\mathrm{X}, \mathrm{HUD})$. The vertical path steering error component of the VNAV performance calculation includes both FTE and display error. For this analysis, it was assumed that display error was negligible so FTE was the only component of vertical path steering error. It was also assumed that the other three components (altimetry system error, vertical path definition error, and horizontal coupling error) of the VNAV performance calculation would be equivalent across the display concepts evaluated. In addition, it was assumed that the pilot was flying a specified vertical profile so that the required vertical navigation performance accuracy was 300 feet (see Table 1).

The HDD SVS concepts (Size A, Size X) yielded a vertical FTE navigational accuracy of 150 feet at least $99.7 \%$ of the time and the HUD SVS concept yielded a vertical FTE navigational accuracy of 100 feet at least $99.7 \%$ of the time. The Baseline concept was unable to yield a vertical FTE navigational accuracy of 300 feet for at least $99.7 \%$ of the time. As such, based on the vertical path FTE distributions, the SVS concepts (Size A, Size X, HUD) would enable RNP-type operations along a specified vertical profile of 300 feet and the Baseline EADI concept would not. Thus, the SVS concepts enhance flight operations by enabling the specification of a flight path vertically for the lateral flight path.

\section{$\underline{\text { Situation Awareness }}$}

SA-SWORD Ratings. Pilots were asked to complete a paired-comparison SA-SWORD ${ }^{10}$. The SA-SWORD for this experiment was designed $b$ allow a statistical analysis of the pilot's subjective assessment of the situation awareness for each of the display configurations (Baseline, Size A Generic, Size A Photo-realistic, Size X Generic, Size X Photorealistic, HUD Generic and HUD Photo-realistic). For this exercise, SA was defined as: The pilot's awareness and understanding of all factors that will contribute to the safe flying of their aircraft under normal and non-normal conditions.

The responses were averaged and the overall rank order was: Size X Photo-realistic, Size X Generic, HUD Photo-realistic, Size A Photo-realistic, Size A Generic, HUD Generic, and Baseline. An ANOVA was performed on the mean rankings with display type and pilot as the independent variables. Display type $(\mathrm{F}(6,18)=6.968, \mathrm{p}<.001)$ was highly significant for this measure. Post hoc tests (using SNK with $\alpha=$ .05) showed that the Size $X$ Photo-realistic had significantly higher SA-SWORD ratings than all other SVS display concepts except for Size X
Generic. Three distinct overlapping subsets were formed: 1) Size X Photo-realistic \& Size X Generic; 2) Size $X$ Generic \& HUD Photo-realistic; and 3) HUD Photo-realistic, Size A Photo-realistic, Size A Generic, HUD Generic, \& Baseline.

\section{Pilot Workload Ratings}

Post-run pilot workload ratings revealed differences among the display concepts $(\mathrm{F}(6,73)=5.594, \mathrm{p}<.001)$. Post hoc tests (using SNK with $\alpha=.05$ ), showed that the Baseline concept imposed significantly more workload on the pilot as compared to the three SVS concepts: Size A, Size X, and HUD. There were no significant differences among the SVS concepts for this measure.

\section{CONCLUDING REMARKS}

The results of this study further confirmed that an SVS display, with pilot-selectable FOVs, could be incorporated as part of an EFIS suite and effectively replace an EADI or PFD. Regardless of HDD display size, and for the daytime, instrument meteorological conditions HUD application, pilots reported greater situation awareness and reduced pilot workload, and had lower flight technical error (FTE) while operating with the SVS displays compared to conventional displays. For both HDD and HUD applications, no significant performance effects were found between texturing techniques.

It was hypothesized that the increased path precision provided by the SVS pathway and pursuit guidance presentation would enable pilots to make manual approaches within RNP accuracies that normally require RNAV capabilities. The lateral navigation analyses confirmed that flight technical error for all the SVS display concepts achieved an accuracy of $0.05 \mathrm{nmi}$ for at least $95 \%$ of the approach compared to just $0.25 \mathrm{nmi}$ for the Baseline condition. The vertical navigation analyses paralleled these results in that for at least $99.7 \%$ of the time, the Size A and Size X concepts achieved a vertical accuracy of 150 feet and the HUD concept achieved a vertical accuracy of 100 feet which are significantly better than the required vertical accuracy of 300 feet. Vertical path control with the Baseline EADI concept (which met required accuracy $89.0 \%$ of time) was outside RNP permissible limits. Based on these results, therefore, synthetic vision would enable manual RNP operations that are five times smaller for lateral RNP and within required vertical performance accuracy values than similar operations with current 757 instruments. The outcome would be 
an increase of RNP operations to runways that otherwise would not meet current Minimum Aviation System Performance Standards (MASPS), resulting in a significant economic advantage to airlines employing SVS technology.,

The NASA Synthetic Vision Eagle-Vail flight test provided valuable research data that have enabled significant improvements to be made to the SVS display concepts. To date, several findings of the flight test have been incorporated into current synthetic vision displays. For example, several pilots suggested that photo-realistic and generic texturing should be combined together to achieve the best that each method has to offer, and a new hybrid texture has been developed that helps achieve this. Other changes include development of several new tunnel concepts and modifications to the HUD to use stroke symbology to better discriminate against raster terrain imagery, particularly, the implementation of a stroke tunnel depiction. NASA researchers have been focused on developing new synthetic vision concepts, such as SVS navigation displays. These are part of a suite of $R \& D$ activities that form the future directions that are being taken to help ensure a "human-centered" synthetic vision system.

A flight test evaluation is anticipated in 2003 by the NASA/Langley Research Center (NASA/LaRC) under NASA's Aviation Safety, Synthetic Vision System Project to examine a synthetic vision system that integrates the enabling technologies (Runway Incursion Prevention System, SV-Sensors, and Database Integrity Monitoring Equipment) of SVS. The research will focus on the integration of runway incursion prevention technologies, surface map displays, integrity monitoring, enhanced vision sensors, SVS navigation displays, and enhanced synthetic vision primary flight and HUD displays.

Together, such a synthetic vision system may considerably help meet national aeronautic goals to "reduce the fatal accident rate by a factor of 5" and to "double the capacity of the aviation system", both with 10 years.

\section{REFERENCES}

1. Boeing (1998). Statistical summary of commercial jet aircraft accidents, Worldwide Operations, 1959-1997. Seattle, WA: Airplane Safety Engineering, Boeing Commercial Airplane Group.

2. Williams, D., Waller, M., Koelling, J., Burdette, D., Doyle, T., Capron, W., Barry, J., \& Gifford,
R. (2001). Concept of operations for commercial and business aircraft synthetic vision systems. NASA Langley Research Center: NASA Technical Memorandum TM-2001-211058.

3. Hemm, R.V. (2000). Benefit estimates of synthetic vision technology. NASA Langley Research Center: NASA Contractor Report NS002S1.

4. Hemm, R.V., Lee, D., Stouffer, V., \& Gardner, A. (2001). Additional benefit estimates of synthetic vision technology. NASA Langley Research Center: NASA Contractor Report NS014S1.

5. RTCA (2000). Minimum Aviation System Performance Standards: Required Navigation Performance for Area Navigation (RTCA DO236A). Washington, D.C.: RTCA, Incorporated.

6. Glaab, L.J., Kramer, L.J., Arthur, T., \& Barry, J.S. (2003). Flight test comparison of synthetic vision display concepts at Dallas/Fort Worth International airport. NASA Langley Research Center: NASA Technical Paper TP-2003212177.

7. Comstock, J.R, Glaab L.J., Prinzel, L.J., \& Elliot, D.M. (2001). Can effective synthetic vision system display be implemented on limited size display spaces. International Symposium on Aviation Psychology.

8. Stark, J., Comstock, J.R., Prinzel, L.J., Burdette, D, \& Scerbo, M.W. (2001). A preliminary examination of situation awareness and pilot performance in a synthetic vision environment. Proceedings of the Human Factors \& Ergonomics Society, 45, 40-43.

9. Merrick, V.K. \& Jeske, J.A. (1995). Flightpath synthesis and HUD scaling for V/STOL terminal area operations. NASA Langley Research Center: NASA Technical Memorandum TM1995-110348.

10. Vidulich, M.A. \& Hughes, E.R. (1991). Testing a subjective metric of situation awareness. Proceedings of the Human Factors \& Ergonomics Society, 35, 1307-1311. 